\title{
The Progress of Biomechanical Researches in Kayaking
}

\author{
Meng Li \\ College of Physical Education, Yangtze University, Jingzhou, China \\ Email: limeng_1222@163.com
}

How to cite this paper: Li, M. (2017) The Progress of Biomechanical Researches in Kayaking. Yangtze Medicine, 1, 30-44. https://doi.org/10.4236/ym.2017.11004

Received: October 25, 2016

Accepted: March 27, 2017

Published: March 30, 2017

Copyright $\odot 2017$ by author and Scientific Research Publishing Inc. This work is licensed under the Creative Commons Attribution International License (CC BY 4.0).

http://creativecommons.org/licenses/by/4.0/

\begin{abstract}
In this review we summarized literatures about biomechanical researches in kayaking. Biomechanical methods provide data on a number of analytical techniques and kayak moving posture for coaches and athletes. 3-D kinematic analysis, on-water dynamic analysis and surface electromyography measurement are the most common methods through which we can assess and describe effects of paddling techniques and training. The purposes of numerous current studies are to identify the factors which restrict kayak performance, make improvement of techniques, prevent and correct mistakes, and develop new type of practical instrument. As a result, we found that although researchers realized the importance of kayaking balance ability and core stability, but balance ability and core stability haven't been considered yet in mechanics analysis and instrument design fields, nor have the research of muscle working status under unsteady state. Our findings through this literature review reveal important directions for further study in the biomechanical researches in kayaking.
\end{abstract}

\section{Keywords}

Biomechanical Research, Kayak, Technology Analysis, Ergometer, Stability

\section{Introduction}

Flatwater kayak is a typical speed competitive event which based on technique, and gives out high level physical capacity through reasonable technical form. After several years' system training and selection, international elite athletes show no obvious differences in physical capacity, therefore the rationality and validity of the personal technology are important factors that affect the elite paddlers' ranking. Biomechanic research aims at finding out excellent and high efficient paddle technology, and providing scientific reference for athletes. The main areas of biomechanical researches reported by domestic and abroad scho- 
lars are listed below (Table 1). The ranking does not reflect the importance of the area. This article will introduce current research situation of these areas.

\section{Rate Strategy Analysis of the Course}

Most of the mechanics researches focus on stroke pace, stroke distance, boat velocity analysis, velocity structure of the course analysis and kayak moving posture analysis. Based on a great number of video and results data analysis, most researchers reach an agreement: for Chinese elite kayakers, the most common velocity structure pattern of $\mathrm{K}-500 \mathrm{~m}$ and $\mathrm{K}-1000 \mathrm{~m}$ is as follows: during starting

Table 1. The main areas of biomechanical researches in Kayaking.

\begin{tabular}{|c|c|c|c|}
\hline NO. & Areas & Concerns & Mainly References \\
\hline \multirow[t]{2}{*}{1} & $\begin{array}{l}\text { Rate Strategy Analysis of the } \\
\text { Course }\end{array}$ & Velocity Structure Pattern & $\begin{array}{c}\text { Ma zuchang et al., 2007; Luo Xu, 2004; } \\
\text { Alacid, F et al., } 2010\end{array}$ \\
\hline & & Pacing Pattern & Leveque, JM et al., 2002; Bishop, D et al., 2002 \\
\hline \multirow{5}{*}{2} & & & Zhong Jinru, 2011; Qian Yongdong , 2006; \\
\hline & & Kinematics Parameters & Liu Gongju et al., 2009; Li Xiaopu et al., 2006; \\
\hline & & Diagnosis & Qiu Yi et al., 2006; Xu Yeli, 2012 \\
\hline & Diagnosis of Kinematics & & Zhong Hongyan, 2008 \\
\hline & & $\mathrm{K}-200 \mathrm{~m}$ & $\begin{array}{l}\text { Xu Yeli \& Pan Huiju, 2009; Wu Guanghong et al. 2013; } \\
\text { Peng Xioaqian, 2011; Zeng Qinglan, } 2012\end{array}$ \\
\hline 3 & $\begin{array}{l}\text { 3-D Analysis of Specific } \\
\text { Technology Action }\end{array}$ & 3-D Plus sEMG & $\begin{array}{l}\text { Mann RV, Keamey JT. 1980; John Baker et al. 1999; } \\
\text { Petrone N et al. 2006; Eloisa L, Roberto S, et al. 2010; } \\
\text { Brown MB et al. 2011; López CL \& Serna JR. 2011; } \\
\text { McDonnell LK et al. } 2012\end{array}$ \\
\hline \multirow[t]{2}{*}{4} & Dynamics Research & on-water test & $\begin{array}{c}\text { Ma Zuchang, 2007; Cao Jingwei et al. 2007; Wang Jingzhi } \\
\text { et al. 2012; Aitken DA \& Neal RJ.1992; } \\
\text { Janssen I \& Sachlikidis A. 2010; Vadai G.et al., } 2013\end{array}$ \\
\hline & & Formula and Simulation Model & Huang Shengchu et al., 1999; Qiu Yi et al., 2011 \\
\hline \multirow[t]{2}{*}{5} & $\begin{array}{l}\text { Application Research of Surface } \\
\text { Electromyography (sEMG) }\end{array}$ & Muscle Working Statuts & $\begin{array}{l}\text { Feng Feihu \& Le Chun, 2010; Luo Dongmei, 2003; } \\
\text { Luo Dongmei \& Liu Ye, 2003; Wang Weixing, 2005; } \\
\text { Trevithick BA et al., 2007; Neil Fleming et al., 2012; }\end{array}$ \\
\hline & Technology & StrengthTraining & $\begin{array}{c}\text { Yang Chunhong et al. 2012; } \\
\text { Yin Xiaoguang \& Wang Weixing, 2010; }\end{array}$ \\
\hline \multirow[t]{2}{*}{6} & Training Equipment Research & Blade & $\begin{array}{l}\text { Mann RV, Keamey JT. 1980; John Baker et al. 1999; } \\
\text { Plagenhoef, S. 1979; Keamey JT, 1979; } \\
\text { Sanders RH \& Kendal SJ.1992a; Sanders RH \& Kendal } \\
\text { SJ.1992b; Kendal SJ \& Sanders RH.1992; Jackson P.1995; } \\
\text { Sanders R \& Baker J.1998; Laurent A, 2013; }\end{array}$ \\
\hline & & Ergomete & $\begin{array}{l}\text { Mitchell A, Swaine IL. 1998; Someren KA, et al. 2000; } \\
\text { Begon M, Colloud F, 2007; Begon M et al., 2009; Begon } \\
\text { M, Colloud F, 2008; Begon M et al. 2009; Begon M, et al. } \\
\text { 2010; Fohanno V et al. 2013; Michael JS, et al. } 2010\end{array}$ \\
\hline
\end{tabular}


phase, athletes will speed up to the maximum through extremely high pace frequency, then turn to midway phase, pace frequency and velocity decrease slowly, to a lower pace frequency and stable rhythm, maintain to a certain speed, while enter to sprint phase, improve the paddle pace frequency again, with reasonable combination of the pace frequency and stroke distance form competitive boat speed [1]-[8]. The more the velocity coefficient value fluctuated during entire course, the use of tactics is more unreasonable, successful tactic shows a relatively stable velocity coefficient value fluctuation [4]. The boat velocity of midway phase highly correlated to the average velocity of entire course, so the dominant ability to successful performance including distributing physical ability reasonably and maintaining well performance during midway phase [5] [6] [9]. The performance of starting phase and sprint phase is also critical, and becomes key factors to successful performance under some extreme competitive circumstances [3]. Increasing stroke frequency in the sprint phase do not necessarily mean improvement of boat velocity, whether the boat velocity growth depends on the average stroke force [1]. Furthermore, by analyzing the performance patterns from the world's best paddlers who took part in the Beijing Olympic Games in 2008, Alacid, F. \& Lopez-Minarro, P.A. found out that pacing strategies and cycle frequency evolution followed a negative trend in all the Olympic races, and there were no significant differences in pacing strategy between heats or semi-finals and finals [10].

Pacing pattern is related with $\mathrm{VO}_{2}$ uptakes in some level. Leveque, J.M., Brisswalter, J. \& Bernard, O. investigated the effect of paddling cadence on $\mathrm{VO}_{2}$ uptake kinetics during a specific kayak exercise [11]. Seven high level paddlers (mean age $22 \pm 1.6$ year) performed a maximal exercise at three different cadences $(50,60$ and 70 cycles.min $(-1))$. And the discussion set out different hypothesis explaining the individual relationship between cadence and oxygen kinetics, in particular a possible effect of cadence change on muscular fiber recruitment pattern. Another study indicated that 2-min kayak ergometer performance is significantly greater following an all-out start strategy when compared with an even-paced strategy [12]. The improved performance appears to be attributable to faster $\mathrm{VO}_{2}$ kinetics, without a significant change in the total accumulated oxygen deficit (AOD) (although the AOD distribution was altered).

\section{Diagnosis of Kinematics}

A lot of researches focus on finding out the deficiencies existing in players by analyzing the kinematics parameters. Zhong Jinru analyzed the segmentation results of final match of kayaking in the 11th National Games, found that many players perform a excessively fast speed during front segment, that lead to an unsustainable boat velocity and have negative impact on sprint performance, there is a big difference between first half course performance and those of the second half course, that indicates the aerobic ability of athletes needs to be strengthened [13]. Qian Yongdong compared and analyzed the paddle technique during entire course between the domestic and the outstanding foreign $\mathrm{K}-500 \mathrm{~m}$ 
players [14], found that stroke distance and stroke frequency deficiencies exist in different segment of the course. Liu Gongju compared and analyzed the stroke rate, stroke point of view, time and displacement on the starting phase and the sprint phase of MK4-1000m between Chinese and foreign athletes [15]. Found that compared with foreign elite team, Chinese athletes have obvious deficiency during midway while have certain advantages in the sprint phase. Li Xiaopu, Wei Wenyi \& Qiu Yi studied the speed component of elite kayakers of K1-500m in the acceleration phase [16], and suggested that technique of velocity gained by improving stroke paddle effect is better match with technical requirement of economical and efficient physical ability structure of elite kayakers. Zhong Hongyan [6] pointed out the deficiency of power during starting phase make paddlers increase their stroke rate desperately during front segment of the course in order to narrow the gap between their competitors, but neglect the efficient of every single stroke, finally cause energy waste, and lead to a backward status in sprint phase. Qiu Yi, Wei Wenyi, Liu Aijie \& Cao Jingwei analyzed the stroke rate modes of the $\mathrm{Wk} 4-500 \mathrm{~m}$ items presented by the main foreign opponents in world great competitions [17], then pointed out the major physical gap in pace performance between national team and main foreign opponents existed in the starting accelerated ability and lactic acid endurance ability. The enhancement of these two kinds of abilities is the key point of pace training. $\mathrm{Xu}$ Yeli classified and described all kinds of sprint features in detail [18], his work provides a helpful reference to kayaking competition which is increasingly fierce.

As a newly added event, K-200m has drawn great attention of scientific researchers as well as coaches and athletes because of its particular characteristics, and most studies suggest that the set sail technology of $200 \mathrm{~m}$ event is highly correlated with the final ranking [19] [20]. By using the SIMI Motion 7.50 Analysis System, Xu Yeli \& Pan Huiju analyzed the characteristics of the forth set of three players' start balance technique of 2010 Shanghai kayak championship single man kayak $200 \mathrm{~m}$ (MK1-200m) final A, B, C [19]. The result showed that the balance status before departure directly affected the final results of the competition, a well balance status will help the players to perform good in the matches, the sway mainly occurs in the shoulder. Wu Guanghong, Liu Gongju \& Fang Haibo [21], pointed out that the exit angle and entry angle of Chinese athletes are very different in both side, and the stability need to be improved. The study of Peng Xioaqian confirmed the above views [22]. Zeng Qinglan analyzed the specific qualities and technology factors which related to high stroke rate technology of kayakers [23].

\section{3-D Analysis of Specific Technology Action}

Specific technology action of kayaking can be described and analyzed by means of 3-D kinematics. Ying Chunyi analyzed paddling technology of outstanding female kayakers, pointed out that for Chinese and foreign WK1 players, based on the relationships between stroke rate, stroke distance and boat velocity, there is no significant correlationship in stroke rate and boat velocity, but do exist a 
moderate correlationship in stroke rate and stroke distance [24] [25]. That means boat velocity increased with the growth of stroke distance. For Chinese and foreign WK2 players, both stroke rate and distance are correlated with boat velocity significantly, indicating that keeping certain stroke rate without loss stroke distance is a key factor in winning the game. Elite kayakers have a trend of increasing pulling phase with a shorten recovery phase. Meanwhile, according to the dynamic characteristics of a paddle movement cycle and referencing other scholars opinions, Ying Chunyi and Peng Xiaoqian bring out a paddle cycle stage division method: one paddle cycle could be divided into four phases-catch, propel, forepart recovery and posterior recovery [22] [24]. Cai Lingli analyzed boat velocity, displacement, paddle angle and various body joints angle, and proposed a reasonable paddling technical feature of single woman kayaking [26]. Other literatures which involving specific movement technology analysis and deconstruction are not very detailed, mostly provided an observational description of general framework, the occurrence and conductive process remains unknown.

Coaches and athletes concern a lot about the details of kayaking technique, therefore researches about kayaking technology are numerous. Restricted by research condition and movement form, most studies conducted on the ergometer simulated on-water paddling intensity and pace, various mechanical parameters were collected and analyzed through 3-D video photography, force sensors or sEMG. Mann, Kearney,\& Kauffman analyzed the technique of 9 Olympic caliber K-1 paddlers using cinematographic and computer procedures, three important positions during paddle circle were investigated (entry, vertical and exit), through which paddler movement, boat proceeding state and the relationship between them were being described [27]. Although this study based on the use of flat blade, it became a very important reference literature for later scholars since its rigorous and detailed analysis and description. John Baker, David Rath, Ross Sanders \& Barry Kelly analyzed 3-D kinematics of male and female elite sprint kayak paddlers [28]. Because of different physical condition, it was a logical finding that there was a significant difference in stroke length and velocity between two genders, but in some important technique parameters no significant differences were found, therefore coaches should not adopt different coaching strategies in training different gender athletes. Petrone N, Isotti A, \& Guerrini G. analyzed the motion pattern and biomechanical parameters of elite female Olympic kayak athletes during indoor paddling on ergometers by using a 3D analysis system and dynamometric footpad [29]. Symmetry and regularity criteria were adopted to define a skill classification for each analysis parameter and a final correlation with sport results classification was investigated. Finally found that the best athletes were able to perform a symmetric, steady and compact trajectory, and a compact symmetric trunk rotation with higher range, also able to increase the forces at increased pace with symmetric footpad force. Consistent evidence came to a similar conclusion: elite paddlers showed higher movement amplitude, higher level of bilateral symmetry, and the lowest ROM of 
pelvis angular movements in the frontal plane with stable posture [30]. Brown \& Lauder studied 135 kayak paddlers with different ability levels using notational analysis, found that significantly greater stroke width, forward reach, trunk rotation and leg motion in the elites [31]. The study suggested paddlers should incorporate greater use of the musculature in the legs and trunk to improve kayak velocity and performance. Based on the 3D mechanical data of stable paddling on ergometer by elite kayakers, C. López López \& J. Ribas Serna quantitatively described the optimal stroke profile by 3D view form (Figure 1) [32]. Descriptions of sprint kayaking stroke phase vary among kayaking literature, and with lots of inconsistencies. Summarized and analyzed previous literatures, McDonnell, Hume \& Nolte proposed that kayaking data should be reported using single strokes and described using water phases and aerial phases. [33]. For more detailed analysis without disrupting the basic two-phase model, a four-sub-phase model consisting of entry, pull, exit, and aerial sub-phases should be used. All the researches above provided very detailed references for us to understand standardized technology of kayaking. Another study pointed out: the average kayak velocity is determined by kayak stroke displacement and stroke time. Stroke time was particularly relevant with 200 -m race time, while average horizontal velocity over two consecutive strokes at race pace was strongly correlated with stroke rate. [34].

\section{Dynamics Research}

Dynamics research reports are rare. By developing an on-water dynamic measuring equipment, someone built a boat testing system which able to provide kinematic and dynamic parameters, with which information such as force, power, stroke rate, stroke rhythm, boat velocity, acceleration and boat posture could be accessed during on-water training, with these data, several issues about kayaking being discussed, such as strength quality, stroke technique, power producing, power protection and so on [35] [36] [37]. According to above research proposed

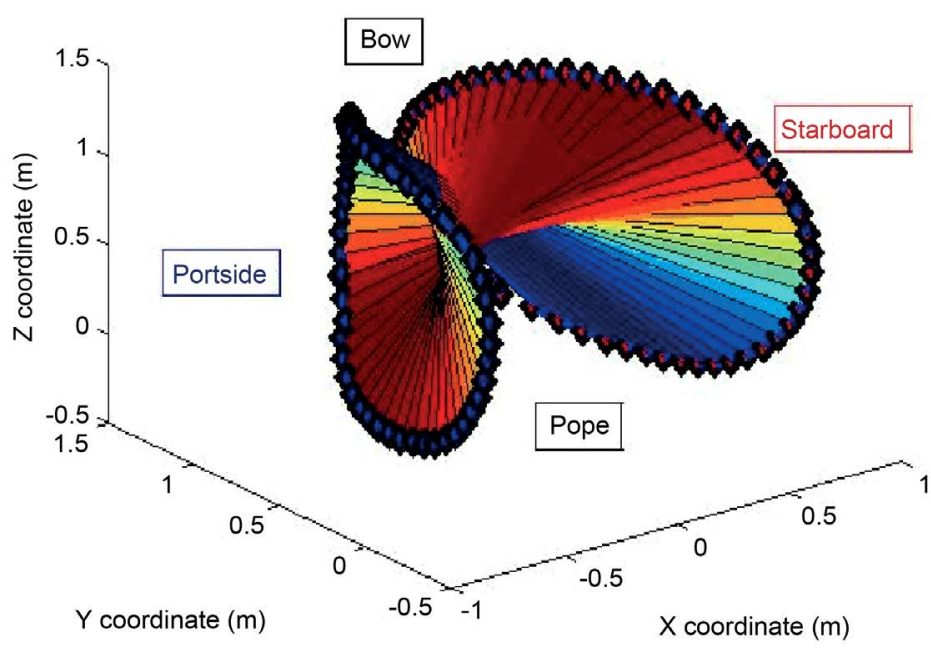

Figure 1. 3D view of optimal stroke profile (C. López López \& J. Ribas Serna, 2011). 
an evaluation indicator system of kayak competitive capability based on paddle force measurement and analysis. Huang Shengchu, Ge Xinfa \& He Yongkang established a complete formula of rowing dynamics, described the relationship between the boat movement and its acting force completely and quantitatively, pointed out that the momentum of the body mass center movement could produce a propulsive force, and result in an important propulsion phase during paddling [38]. Qiu Yi, Wang Yang, Zhou Meifang, Cheng Qilian \& Wei Wenyi studied the effect of kayaker's impelling power mode on performance in K1-1000m with even pace paddling by Matlab/Simulink simulation model and numerical methods on the basis of dynamic equation for kayak, found that there are differences between actual impelling power wave shapes in paddling force of domestic elite male kayakers and ideal impelling power wave shape resulted from simulation analysis, which implied paddling skills and enhance physical capacities for those kayakers need to be improved [39]. The studies mentioned above enriched the knowledge of kayaking greatly, but there is no thorough investigation about the paddler's muscle working and controlling situation.

The mechanics data of kayaking have great importance to competition and training. As early as 1992, Aitken, DA \& Neal, RJ developed an on-water analysis system for quantifying stroke force characteristics during kayaking, which could presented the paddlers' force time curve and give report on the paddlers' kinetics index data [40]. The acceleration of boat is an important parameter of paddler performance, Janssen \& Sachlikidis compared a kayak-mounted GPS-based accelerometer unit to the video-derived measurement, the study highlights the need for sports utilizing GPS-based accelerometers, such as minimaxX, for intra-stroke measurements to conduct sport-specific validity and reliability studies to ensure the accuracy of their data [41]. G Vadai \& G Makan developed a microcontroller-based expandable system which can record the kayak's motion accurately [42]. The system including the built-in 3-axis accelerometers, gyroscopes and various optional sensors, and software platform especially developed for the evaluation of the performance of kayak paddlers. Many experiments proved that it's accurate, portable, practical and helpful.

\section{Application Research of Surface Electromyography (sEMG) Technology}

The technology of sEMG is widely used in sports science research recently, mainly focus on the study of muscle strength and muscle fatigue, muscle reaction time (RT), analysis of the muscle activity function, muscle coordination, muscle fiber composition, muscle contraction speed and muscular stability [43]. Qu Feng discussed the method of analyze athlete's sEMG and used linear forecasting method to predict link torque in details, which provided method guidance for applying sEMG technology in the field of sports [44]. Evaluate muscle function by using sEMG technology has become an important means of assessing the locomotor system function. The reports of domestic research about applicating sEMG technology to the sport of kayaking are rare. Feng Feihu and Le Chun identified several mainly worked muscles by analyzing sEMG characteris- 
tics produced in indoor $1000 \mathrm{~m}$ imitating paddling by kayakers, and pointed out the iEMG signal changing was similar to the changing of stroke rate, therefore, to a certain extent, sEMG signals could reflect the exercise intensity [45].

The working status of dominating muscle groups during a stroke cycle including contraction strength, muscle activation sequence, coordination and balance of bilateral body sides, etc., could be measured by combination use of sEMG technology and 3-D video technology, furthermore, kayaking technology could be elaborated and deconstructed from human body dynamic system. Luo Dongmei took 48 kayak national team athletes preparing for the Athens Olympics as research subjects, tested and analyzed their paddle movement and technical structure by use of sEMG, QUALisys-Mcu500 infrared long shots testing system and 3D video recording and analyzing system, and explored the action structure, motion trajectory, dominating muscle groups' contract pattern and activation sequence of national kayakers, and designed special strength training methods for key technology [46] [47]. sEMG study found that, in paddle movement of kayaking, the motion pattern and amplitude of upper limbs are far more than the trunk and lower limbs, so the upper limb muscle, mainly shoulder muscles and the muscles of the upper arm, have the largest working ratio, such as during pulling phase, the back bundle of deltoid, the triceps, the infraspinatus, and the latissimus dorsi, etc.; as well as the pectoralis major, the anterior bundle of deltoid and the biceps during recovering phase. The muscles working for trunk rotating (reverse) and maintain posture are in secondary ratio, such as trunk rotating muscle-the obliquus externus abdominis, and posture maintainer-erector spinae. The muscles of the lower limb such as the tibialis anterior, the biceps femoris and the rectus femoris which dominating buckling, stretching are in the third place. The sEMG analysis of lower limb muscles during $500 \mathrm{~m}$ maximum on-water paddling by elite women kayaker-Zhong Hongyan indicated that core stability, especially the ability of the obliquus externus abdominis is indispensible in all three segments of starting, midway and sprint phase. All these muscle groups not only create a fulcrum for upper limbs to coordinate its force and control its action, but also become a central area of which paddling movement force generated and transmitted, and also the middle link of the kinetic-chain which combines the upper and lower body as well as human and boat [5] [48]. These studies provided valuable information for us to understanding muscle work situation and specific technology motion in kayaking.

EMG data could also provide guidance for specific aimed strength training. Taking swimming athletes as subjects, the specificity of gravitational resistance (GR) and hydraulic resistance (HR) was compared by analyzing sEMG of rectus femoris during knee extension. Hydraulic resistance has a characteristic of slower peak timing and longer duration. It might offer an unique advantage for enhancing specific strength in swimmers and rowers. Athletes of such sports should develop their specific strength by utilizing hydraulic devices more frequently [49].

Few experiments provided important reference for understanding the inter-dynamic mechanism of movement technology by studied the working status 
of some muscle groups during paddling by sEMG. A research group studied shoulder muscle recruitment patterns during a kayak ergometer paddling, found that: Latissimus dorsi, supraspinatus and upper trapezius demonstrated a consistent recruitment pattern during pull through phase [50]. Latissimus dorsi activity increased to maximum value in mid pull through phase. The upper trapezius contributes to scapular and glenohumeral joint stability. Serratus anterior, rhomboid major and latissimus dorsi recruit a lot during exit phase. Although sEMG indicated that all these muscles' activity decreased, upper trapezius and supraspinatus demonstrated a consistent recruitment pattern during recovery phase. For the purpose of finding out the differences of paddling technology of on-ergometer and on-water kayaking, Neil F, Bernard D, David F \& Nick M. compared EMG, stroke force and 2D kinematics of 10 male elite flatwater kayakers during on-ergometer and on-water kayaking [51]. Founding that: compared with on-water data, significantly greater anterior deltoid mean iEMG activity was recorded on-ergometer $(\mathrm{p}<0.01)$, while lower triceps brachii and latissimus dorsi activity were recorded on-water $(\mathrm{p}<0.01)$. The reason might be the ergometer loading mechanism, it's also an evidence of ergometer simulated the on-water scenario inaccurately in biomechanical aspect.

Lots of literatures about kayaking technology agreed that "symmetry", "stability" contribute to well performance, but no research was found in seeking main factors of maintain technique stable, how to control kayak balance on water, and keep movement stable. The most related literature is a paper about postural stability of canoeing and kayaking young male athletes during quiet stance, pointed that affected by different sport character, the canoeing and kayaking athletes show different postural stability. Thus far there is no research about kayaking stability training being reported [52].

\section{Training Equipment Research}

It's an interesting research field of how different shapes of blade affect paddle effect. Since the introduction of the wing paddle in the mid-1980s sprint kayaking has undergone an evolution in technique [28]. While a number of studies have examined paddling technique using the flat blade [27] [53] [54], new research conducted into the technique of using the wing blades, and found the character of outstanding paddle technique is as follow: The blade tip and joint center paths move consistently across trials. High performance paddlers entered their blade well forward and closer to the longitudinal axis of the boat, and paddle the blade a large distance laterally from the kayak while a small distance backward [55] [56] [57]. Jackson mathematically modeled the wing blade to discover that the wing blade had a $15 \%$ higher efficiency than the conventional flat blade (wing blade 89\%; flat blade 74\%) [58]. In addition Sanders \& Baker provided a theoretical perspective on why the wing blade is superior to the flat blade [59]. Laurent A, Rouard A, Mantha VR, Marinho DA, Silva AJ, \& Rouboa AI. conducted an experiment to study pressure coefficient of oar blade in steady flow conditions $(4 \mathrm{~m} / \mathrm{s})$. They used the computational fluid dynamics (CFD) 
technique to calculate the pressure of the flow around the oar blade for different angular orientations of the oar ( 45 degrees, 90 degrees, 135 degrees). The results show that CFD could be a useful tool to evaluate the effects of different shapes of blade and contribute lot in blade designing. The variation of pressure coefficient dependent on angular position of oar gave important dynamic information to kayak coach and players. [60].

As an important specific training tool, kayak ergometer plays a very important role in kayak training, which used by coaches and athletes all over the world for their training. Investigations into the validity of on-ergometer versus on-water testing for metabolic and cardiorespiratory variables $\left(\mathrm{VO}_{2}\right.$, heart rate and blood lactate) have concluded that while kayak ergometers accurately simulated physiological demands of short-term high intensity kayaking [61] [62]. Meanwhile, researchers focused on developing new type of ergometer which could more accurately simulated the on-water scenario in biomechanical character. Mickaël Begon used an ergometer with sliding footrest-seat complex to simulate the on-water mechanical condition (Figure 2) [63] [64] [65]. Defines the mechanical system of athlete paddling on the ergometer as the system athlete-paddle $\{\mathrm{AP}\}$, five external forces act $\{\mathrm{AP}\}$ : weight, aerodynamic drag and three contact forces (blades, seat and footrest), in theory, the contact force patterns reproduce those generated on-water if $\{\mathrm{AP}\}$ 's acceleration is similar. Based on above theory, Begon transformed fixed-seat ergometer to a sliding-trolley ergometer, instrumented by several force sensors for mechanical data collecting. While compared the $\{\mathrm{AP}\}$ 's acceleration of these two ergometer to on-water acceleration using computer simulation, they found that sliding-trolley ergometer is more similar to on-water condition. At the paddle verticality, there is a difference of $2 \mathrm{~m} / \mathrm{s}^{-2}$ between on-water and fixed-seat condition. This causes extra forward forces on the settings of about $150 \mathrm{~N}$. Moreover, fixed-seat condition leads to positive acceleration for aerial phases. These differences may cause modification of muscular coordination. As a result, the degree of freedom in translation for the trolley is an important parameter to consider for ergometer design. In another investigation a strong relationship between performances on flatwater and performances on an ergometer was established by means of propulsive force measurement and drag models [66]. Using this method, kayakers can be compared

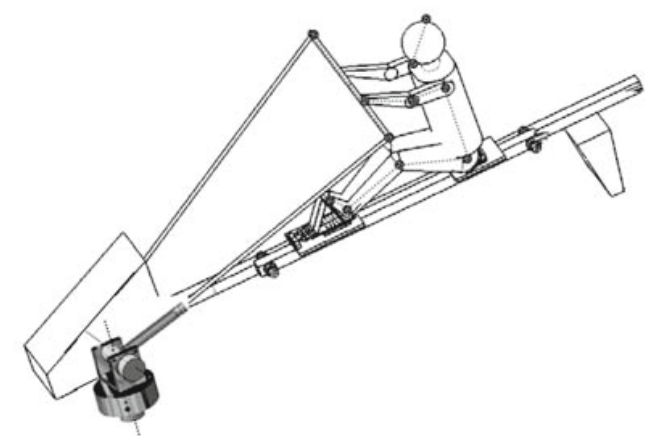

Figure 2. Kayaking ergometer with the sliding trolley. (Mickaël Begon et al. 2009). 
to each other on the instrumented ergometer in a way that corresponds to their performance on flatwater. Lower limb contribution in flatwater kayaking is less known by people because kayaking always being thought as an upper limb dominated sport. While designing sliding-trolley ergometer, a study group analyzed the lower limb contribution in kayak performance [67]. A computer simulation model was developed based on ergometer paddling movement of 12 male athletes with international experience of flatwater kayaking, the significant contribution of the lower limb asymmetrical motions in the kayaking performance and efficiency were highlighted by the results. The pedalling motion in flatwater kayaking increased the performance by $6 \%$ and reduced the internal work by $4 \%$. Since the paddle movement possessing the character of closed-loop movement pattern, Vincent Fohanno, Mickaël Begon, Patrick Lacouture \& Floren Colloud developed a computer simulation model of paddling technique, and finally established optimum algorithms for estimating body joint kinematics with closed-loop constraints [68]. J.S. Michael and colleagues compared the physiological characteristics of flatwater kayaking between traditional fixed seat and novel swivel seat, found that paddling with the swivel seat lead to about $6.5 \%$ increase in power output. This might be a significant advantage during on-water competition if the results from present ergometer test transfer [69].

It's worth mention that what Begon and his colleagues do is a long-term and systematic work, they do a series related research while designing new type of ergometer which could more accurately simulated the on-water scenario, and gave out several meaningful methodology reference.

However, it's difficult to put these achievements into use yet. Firstly because the components of force sensors and computer aids software needed by the research remained unknown in details. In addition, the theoretical basis of the research is pure physical modeling based on ideal condition, without the consideration of the instability and balance controlling while sailing on water.

\section{Conclusion}

Biomechanic method provides a number of data of analytical techniques and kayak moving posture, and gives some useful guidance. We can come to the conclusion from above that the biomechanical technology used in kayaking mainly focus on the analysis of kinematics parameters by $3 \mathrm{D}$ video recording and analyzing, providing standardized technology reference. A few scholars trying to develop new ergometer which can simulated on-water scenario more accurately. Newly progress of some related researches indicated that symmetry of both side, balance ability and core stability play an important role in kayaking performance. Although with more understanding of the character of kayaking, more attention were drawn to these factors, but less consideration was given in mechanics analysis and instrument design fields, neither the research of muscle working status under unsteady state. It will be an interesting trying to transplant the character of unstability while paddling on water to an ergometer. Theoretically, we can expect better kayaking performance if we can imitate the mechan- 
ism of this factor successfully during daily training. So far it is a task that needed further study.

\section{References}

[1] Ma, Z.C., Cao, J.W., Liu, A.J., Sun, Y.N. and Mei, T. (2007) Study on Competitive Velocity Structure and Strategy of Man's K-1 500m. China Sport Science, 27, 47-51.

[2] Lu, R., Xiao, Q., Qiu, Y. and Cheng, X.Z. (2012) The Study on the Strategy Disciplinarian and Pace Profile in Competitions on Flat Water Canoe. Journal of Anhui Sports Science, 154, 35-39.

[3] Ding, J.J., Pang, H.J. and Xu, Y.L. (2010) Study on Competitive Velocity Structure and Stroke Rate Pattern of Woman's K-1 500m of the 11th National Games. Sport, $12,18-19$.

[4] Shen, H. (2012) The Tactic Research on Men's 1000m Kayak in the 11th National Games. Thesis, Wuhan Institute of Physical Education, Wuhan.

[5] Yin, X.G., Wang, W.X. and Zhang, X.H. (2010) The Research on the Characteristics of Canoe/Kayak in Flat-Water Event. Journal of Beijing Sport University, 33, 106-110.

[6] Zhong, H.Y. (2008) A Study of Speed Construction of Women's 500m kayak. Journal of Beijing Sport University, 31,913-918.

[7] Luo, X., Guan, J.C., Zhang, Q. and Zhou, F.T. (2005) The Elite Chinese WK1\MK1 and MC1 Canoeists' Competitive Velocity Structure of 1000m. Journal of Beijing Sport University, 27, 1496-1497.

[8] Zhang, H., Wang, Y.H. and Cao, X.X. (2005) Competition Strategy of Excellent Canoeists. Journal of Wuhan Institute of Physical Education, 39, 74-76.

[9] Jiang, C., Liu, G.J., Jiang, X.W. and Fang, H.B. (2010) Speed Structure in the WK4-500m Finals of the 11th National Games. Sport Science Research, 31, 24-27.

[10] Alacid, F., Lopez-Minarro, P.A. and Isorna, M. (2010) Pacing Strategy and Cycle Frequency in Canoeing at Beijing Olympic Games. Revista Internacional de Medicina y Ciencias la Actividad Fisica y del Deporte, 38, 203-217.

[11] Leveque, J.M., Brisswalter, J. and Bernard, O. (2002) Effect of Paddling Cadence on $\mathrm{VO}_{2}$ Uptake Kinetics during a Specific Kayak Exercise. Science and Sport, 17, 95-97.

[12] Bishop, D., Bonetti, D. and Dawson, B. (2002) The Influence of Pacing Strategy on $\mathrm{VO}_{2}$ and Supramaximal Kayak Performance. Medicine \& Science in Sports \& Exercise, 34, 1041-1047. https://doi.org/10.1097/00005768-200206000-00022

[13] Zhong, J.R. (2011) The Comparative Research of the Canoeing Final Segmentation Results in the 11th National Sports Games. Hubei Sports Science, 30, 477-478.

[14] Qian, Y.D. (2006) Analysis of the Full-Distance Techniques of Our Excellent Canoeists. Thesis, Beijing Sport University, Beijing.

[15] Liu, G.J. and Pan, H.J. (2009) The Kinematics Analysis on the Sets Sail, the Spurt Stage of 1000 m MK4 Kayak between Chinese and Foreign Male Athletes. Zhejiang Sport Science, 31, 116-121.

[16] Li, X.P., Wei, W.Y. and Qiu, Y. (2006) Study on Speed Component of Elite Kayakers of K1-500m in the Acceleration Phase. China Sport Science and Technology, 42, 119-121.

[17] Qiu, Y., Wei, W.Y., Liu, A.J. and Cao, J.W. (2006) Comparative Studies on the Stroke Rate Modes during the Full Performance of Chinese and Foreign Women Kayak Four in $500 \mathrm{~m}$ Competitions. Journal of Xi an Institute of Physical Education, 23, 93-96.

[18] Xu, Y.L. (2012) The Study of Sprint Features of Canoe-Kayak (Still Water). Thesis, 
Zhejiang Normal University, Jinhua, Zhejiang.

[19] Xu, Y.L. and Pan, H.J. (2011) Comparative Study on Balance Technique in Start Stage of Chinese Single Man 200 m Kayak Players. Journal of Tianjin University of Sport, 26, 27-29.

[20] Zhang, B.X., Pan, H.J. and Ge, G.W. (2012) Comparative Study on Set Sail Technique of Chinese Single Man Kayak 200 m Project. Hubei Sports Science, 31, 578580.

[21] Wu, G.H., Liu, G.J. and Fang, H.B. (2013) The Departure Technical Analysis of Men 200 m Single Kayak. Zhejiang Sport Science, 35, 60-65.

[22] Peng, X.Q. (2011) The Study on Set Sail Technology and Competition Strategy of Kayak (Still Water). Thesis, Zhejiang Normal University, Jinhua, Zhejiang.

[23] Zeng, Q.L. (2012) The Study of High Stroke Rate in Kayaking. Science \& Technology Information, 1, 666-667.

[24] Ying, C.Y. (2006) Kinematic Analysis of Outstanding Flat Water Woman Kayakers' Paddling Skill in and out of China. PhD Thesis, Zhejiang Normal University, Jinhua, Zhejiang.

[25] Ying, C.Y., Pan, H.J. and Liang, H.D. (2009) Paddle Stroke Frequency and Rhythm of Chinese and Foreign Elite Single Woman Kayakers. Journal of Shandong Institute of Physical Education and Sports, 25, 47-49.

[26] Cai, L.L. (2010) Three-Dimensional Kinematic Analysis of Single Woman Kayakers' Paddling Skill of Zhejiang Province. Thesis, Zhejiang Normal University, Jinhua, Zhejiang.

[27] Mann, R.V. and Keamey, J.T. (1980) A Biomechanical Analysis of the Olympic-Style Flatwater Kayak Stroke. Medicine \& Science in Sports \& Exercise, 12, 183 188. https://doi.org/10.1249/00005768-198023000-00010

[28] Baker, J., Rath, D., Sanders, R. and Kelly, B. (1999) A Three-Dimensional Analysis of Male and Female Elite Sprint Kayak Paddlers. 17 th International Symposiums on Biomechanics in Sports, 1.

[29] Petrone, N., Isotti, A. and Guerrini, G. (2006) Biomechanical Analysis of Olympic Kayak Athletes During Indoor Paddling. In: Moritz, E.F. and Haake, S., Eds., The Engineering of Sport 6, Springer, New York, 413-418. https://doi.org/10.1007/978-0-387-46050-5_73

[30] Limonta, E., Squadrone, R., Rodano, R., Marzegan, A., Veicsteinas, A., Merati, G. and Sacchi, M. (2010) Tridimensional Kinematic Analysis on a Kayaking Simulator: Key Factors to Successful Performance. Sport Sciences for Health, 6, 27-34. https://doi.org/10.1007/s11332-010-0093-7

[31] Brown, M.B., Lauder, M. and Dyson, R. (2011) Notational Analysis of Sprint Kayaking: Differentiating between Ability Levels. International Journal of Performance Analysis in Sport, 11, 171-183.

[32] López, C.L. and Serna, J.R. (2011) Quantitative Analysis of Kayak Paddling Technique: Definition of an Optimal Stroke Profile. Revista Andaluza de Medicina del Deporte, 4, 91-95.

[33] McDonnell, L.K., Hume, P.A. and Nolte, V. (2012) An Observational Model for Biomechanical Assessment of Sprint Kayaking Technique. Sports Biomechanics, 11, 507-523. https://doi.org/10.1080/14763141.2012.724701

[34] McDonnell, L.K., Hume, P.A. and Nolte, V. (2013) A Deterministic Model Based on Evidence for the Associations between Kinematic Variables and Sprint Kayak Performance. Sports Biomechanics, 12, 205-220.

https://doi.org/10.1080/14763141.2012.760106 
[35] Ma, Z.C. (2007) Study of Sport Biomechanical Information Acquisition and Evaluation Indicators System for Canoe Events. PhD Thesis, University of Science and Technology of China, Hefei, Anhui.

[36] Cao, J.W., Ma, Z.C., Liu, A.J., Yuan, S.L., Sun, Y.N. and Mei, T. (2007) Research on the Evaluation Methods of Kayak Event Skills Based on Kinetic and Kinematical Parameters. Journal of Beijing Sport University, 30, 1122-1125.

[37] Wang, J.Z., Ma, Z.C., Yao, Z.M. and Sun, Y.N. (2012) Evaluation Indicator System of Kayak Competitive Capability Based on Paddle Force Measurement and Analysis. China Sport Science, 32, 55-61.

[38] Huang, S.C., Ge, X.F., He, Y.K., Zhang, H.J., Feng, X.F. and Xu, J.S. (1999) On the Establishment of Rowing Dynamics Formula. Journal of Wuhan Institute of Physical Education, 132, 39-42.

[39] Qiu, Y., Wang, Y., Zhou, M.F., Cheng, Q.L. and Wei, W.Y. (2011) The Numerical Simulation Study on the Effect of Kayaker's Impelling Power Mode on Specific Performance. China Sport Science and Technology, 47, 90-99.

[40] Aitken, D.A. and Neal, R.J. (1992) An On-Water Analysis System for Quantifying Stroke Force Characteristics during Kayak Events. Journal of Applied Biomechanics, 8, 165-173. https://doi.org/10.1123/ijsb.8.2.165

[41] Janssen, I. and Sachlikidis, A. (2010) Validity and Reliability of Intra-Stroke Kayak Velocity and Acceleration Using a GPS-Based Accelerometer. Sports Biomechanics, 9, 47-56. https://doi.org/10.1080/14763141003690229

[42] Vadai, G., Makan, G., Gingl, Z., Mingesz, R., Mellár, J., Szépe, T. and Csamangó, A. (2013) On-Water Measurement and Analysis System for Estimating Kayak Paddlers' Performance. The 36th International Conference of the Microelectronics, Electronics and Electronic Technology, Opatija, 2013, 144-149.

[43] Yu, Z.B., Li, Q., et al. (2010) Skeletal Muscle form and Function. Vol. 1, Fourth Military Medical University Press, Xi'an, 243-250.

[44] Qu, F. (2006) Surface Electromyography and Fractal of Athletes. PhD Thesis, Beijing Sport University, Beijing.

[45] Feng, F.H. and Le, C. (2010) Analyses and Utility of SEMG Produced in Indoor $1000 \mathrm{~m}$ Imitating Paddling by Kayak Athletes. Journal of Wuhan Institute of Physical Education, 44, 63-66.

[46] Luo, D.M. (2003) Lecture of Muscle Working Analysis in Kayaking. Internal Materials.

[47] Luo, D.M. and Liu, Y. (2003) The Feature of Kayak Movement Technology and Study and Application of Specific Strength Training. Internal Materials.

[48] Wang, W.X. (2005) Characteristics and Practice of Physical Performance Training for Canoe Men of China in 2004. Journal of Shandong Institute of Physical Education and Sports, 21, 5-8.

[49] Yang, C.H., Wang, J. and Tao, R. (2012) The Resistance Specificity of sEMG Parameters under Non-Fatigue Contractions. Journal of Beijing Sport University, 35, 59-61, 68 .

[50] Trevithick, B.A., Ginn, K.A., Halaki, M. and Balnave, R. (2007) Shoulder Muscle Recruitment Patterns during a Kayak Stroke Performed on a Paddling Ergometer. Journal of Electromyography and Kinesiology, 17, 74-79. https://doi.org/10.1016/j.jelekin.2005.11.012

[51] Neil, F., Bernard, D., David, F. and Nick, M. (2012) A Biomechanical Assessment of Ergometer Task Specificity in Elite Flatwater Kayakers. Journal of Sports Science \& Medicine, 11, 16-25.

[52] Stambolieva, K., Diafas, V., Bachev, V., Chirstova, L. and Gatev, P. (2012) Postural 
Stability of Canoeing and Kayaking Young Male Athletes during Quiet Stance. $E u$ ropean Journal of Applied Physiology, 112, 1807-1815.

https://doi.org/10.1007/s00421-011-2151-5

[53] Plagenhoef, S. (1979) Biomechanical Analysis of Olympic Flatwater Kayaking and Canoeing. Research Quarterly, 50, 443-459.

[54] Keamey, J.T., Klein, L. and Mann, R. (1979) The Elements of Style: An Analysis of the Flatwater Canoe and Kayak Stroke. Canoe, 7, 18-20.

[55] Sanders, R.H. and Kendal, S.J. (1992) A Description of Olympic Flatwater Kayak Stroke Technique. Australian Journal of Science and Medicine in Sport, 24, 25-30.

[56] Sanders, R.H. and Kendal, S.J. (1992) Quantifying Lift and Drag Forces in Flatwater Kayaking. Proceedings of the 10 th International Symposium on Biomechanics in Sports, Milan, Italy, 1992.

[57] Kendal, S.J. and Sanders, R.H. (1992) The Technique of Elite Flatwater Kayak Paddlers Using the Wing Paddle. Journal of Applied Biomechanics, 8, 233-250. https://doi.org/10.1123/ijsb.8.3.233

[58] Jackson, P. (1995) Performance Prediction for Olympic Kayaks. Journal of Sports Sciences, 13, 239-245. https://doi.org/10.1080/02640419508732233

[59] Sanders, R. and Baker, J. (1998) Evolution of Technique in Flatwater Canoeing. In: Issurin, V., Ed., Science \& Practice of Canoe/Kayak High-Performance Training, Tel Aviv, Israel, 67-81.

[60] Laurent, A., Rouard, A., Mantha, V.R., Marinho, D.A., Silva, A.J. and Rouboa, A.I. (2013) The Computational Fluid Dynamics Study of Orientation Effects of Oar Blade. Journal of Applied Biomechanics, 29, 23-32.

https://doi.org/10.1123/jab.29.1.23

[61] Mitchell, A. and Swaine, I.L. (1998) Comparison of Cardiorespiratory Responses to Open-Water and Simulated Kayaking. Biology of Sport, 15, 229-236.

[62] Someren, K.A., Phillips, G.R.W. and Palmer, G.S. (2000) Comparison of Physiological Responses to Open Water Kayaking and Kayak Ergometry. International Journal of Sports Medicine, 21, 200-204. https://doi.org/10.1055/s-2000-8877

[63] Begon, M. and Colloud, F. (2007) A Kayak Ergometer Using a Sliding Trolley to Reproduce Accurate On-Water Mechanical Conditions. Journal of Biomechanics, 40, S439. https://doi.org/10.1016/S0021-9290(07)70432-3

[64] Begon, M., Colloud, F. and Lacouture, P. (2009) Measurement of Contact Forces on a Kayak Ergometer with a Sliding Footrest-Seat Complex. Sports Engineering, 11, 67-73. https://doi.org/10.1007/s12283-008-0011-2

[65] Begon, M. and Colloud, F. (2008) Optimised Preliminary Design of a Kayak Ergometer Using a Sliding Footrest-Seat Complex. The Engineering of Sport, 7, 171-177.

[66] Begon, M., Mourasse, O. and Lacouture, P. (2009) A Method of Providing Accurate Velocity Feedback of Performance on an Instrumented Kayak Ergometer. Sports Engineering, 11, 57-65. https://doi.org/10.1007/s12283-008-0012-1

[67] Begon, M., Colloud, F. and Sardain, P. (2010) Lower Limb Contribution in Kayak Performance: Modelling, Simulation and Analysis. Multibody System Dynamics, 23, 387-400. https://doi.org/10.1007/s11044-010-9189-8

[68] Fohanno, V., Begon, M., Lacouture, P. and Colloud, F. (2013) Estimation Joint Kinematics of a Whole Body Chain Model with Closed-Loop Constraints. Multibody System Dynamics, 31, 433-449.

[69] Michael, J.S., Smith, R. and Rooney, K. (2010) Physiological Responses to Kayaking with a Swivel Seat. International Journal of Sports Medicine, 31, 555-560.

https://doi.org/10.1055/s-0030-1252053 
Submit or recommend next manuscript to SCIRP and we will provide best service for you:

Accepting pre-submission inquiries through Email, Facebook, LinkedIn, Twitter, etc. A wide selection of journals (inclusive of 9 subjects, more than 200 journals)

Providing 24-hour high-quality service

User-friendly online submission system

Fair and swift peer-review system

Efficient typesetting and proofreading procedure

Display of the result of downloads and visits, as well as the number of cited articles Maximum dissemination of your research work

Submit your manuscript at: http://papersubmission.scirp.org/

Or contact ym@scirp.org 